\title{
PENENTUAN TINGKAT DEPRESI KARYAWAN MENGGUNAKAN METODE CERTAINTY FACTOR
}

\author{
S. Saifulloh ${ }^{1}$ \\ ${ }^{1}$ Universitas PGRI Madiun, Jl. Auri No. 14-16 Madiun Telp/Fax (0351) 462986 / (0351) 459400 \\ ${ }^{1}$ Program Studi Sistem Informasi, Fakultas Teknik, UNIPMA \\ E-mail: saifulloh@unipma.ac.id
}

\begin{abstract}
Abstrak - Berdasarkan data WHO, depresi berada pada peringkat ketiga beban penyakit dalam skala global mulai dari th 2014 dan diprediksi cenderung mengalami peningkatan peringkat tertinggi dalam skala global dunia pada th 2030. Depresi merupakan kondisi yang menyebabkan seseorang kehilangan konsentrasi dan daya fikir, sulit mengambil keputusan, mudah kecewa, marah, dan tersinggung yang mengakibatkan terkadang tidak menyadari jika dirinya mengalami problem depresi. Gejala pada depresi biasanya ditandai dengan kehilangan semangat dan motivasi, semangat yang buruk, serta makin menurunnya energi dan stamina untuk beraktivitas. Stres berat di kantor dengan bermacam kegiatan dan aktifitas kerja dapat berujung pada depresi klinis atau justru memperparahnya, yang lama kelamaan dapat merugikan kinerja karyawan, hal ini juga dapat berpengaruh terhadap tempat dimana seseorang tersebut bekerja. Banyak faktor yang berpengaruh sehingga meningkatkan hormon-hormon yang meyebabkan stress dan depresi (adrenalin, norepinephrine, kortisol), Perasaan negatif, baik stres, kemarahan, dan lainnya bisa muncul akibat kinerja tiga hormon tersebut. Peningkatan kerja hormon dapat mengganggu kondisi tubuh sehingga berpengaruh terhadap daya fikir seseorang, meski begitu dalam beberapa kasus hormon ini juga sangat bermanfaat bagi tubuh.
\end{abstract}

Kata kunci - Stres, Depresi, Karyawan, Pengambilan Keputusan

\section{PENDAhUluan (INF_HEAding 1)}

Pada era global sekarang, sering kita dengar maupun kita temui masalah-masalah yang terkait dan berhubungan dengan depresi, pola pikir dan cara hidup yang salah dapat memicu kondisi dimana seseorang menjadi sangat depresi. Permasalahan ekonomi, terlalu berat bekerja, stress dengan pekerjaan dll, sangat sering kita dengar dan bisa berpotensi buruk. Dampak lain dari depresi ialah adanya penurunan semangat bekerja, bergaul dan nafsu seksual [1]. Problem kesehatan jiwa di indonesia merupakan permasalahan yang sangat penting untuk kesehatan masyarakat dan harus mendapatkan perhatian khusus agar tingkat gangguan jiwa berpotensi berkurang untuk segera mendapat solusi dan penanganan. Perkembangan teknologi yang semakin pesat haruslah didukung dengan skill yang mumpuni agar dapat dimanfaatkan dengan baik dan digunakan secara berimbang antara fungsi dan manfaatnya[2]. Dengan pemanfaatan yang tepat kita dapat menggunakan kecanggihan teknologi ini sebagai sarana dalam mengembangkan kreatifitas juga sebagai sarana mempelajari faktor-faktor yang dapat mengurangi dan mencegah depresi. Seperti halnya digunakan dalam metode penelitian untuk mengukur tingkat depresi karyawan pada sebuah perusahaan dengan menggunakan metode certainly faktor. Metode certainly faktor diperkenalkan oleh Shortliffe Buchanan sekitar tahun 1975 digunakan untuk menganalisa tentang ketidakpastian pola pemikiran (inexact reasoning) oleh seorang pakar atau ahli[3].

\section{LANDASAN TEORI}

\subsection{Definisi Sistem Pakar}

Sistem pakar merupakan sebuah program komputer yang dirancang sebagai permodelan kemampuan berfikir seorang pakar yang menggunakan pengetahuan, fakta dan teknik penalaran untuk penyelesaian masalah [4]. Dengan sistem ini seorang user dapat menyelesaikan masalah yang cukup rumit tanpa harus melibatkan seorang pakar atau ahlinya. Sistem pakar memudahkan seseorang untuk memecahkan masalah, tujuan dasar dari suatu pembuatan perancangan sistem ini adalah merupakan pengembangan pengetahuan dari pakar dan sebenarnya bukan untuk menggantikan peran manusia lebih tepatnya untuk mensubsitusikan pengetahuan kedalam bentuk sistem sehingga dapat digunakan oleh orang banyak tanpa harus memikirkan biaya untuk konsultasi pakar[5].

\subsection{Depresi}

Depresi bisa dikatakan merupakan respon normal terhadap stres kehidupan atau suatu keadaan emosi seseorang yang tidak stabil dan tidak menyenangkan karena disebabkan oleh suatu peristiwa yang tidak diinginkan, dimana keadaan ini dapat beresiko ringan hingga tingkat yang sangat berat [6] Depresi terjadi karena pengaruh sirkuit neural, termasuk ketegangan yang bersumber dari kombinasi kondisi biologis, psikologis, dan sosial. Faktor ini juga dapat menyebabkan perubahan dalam fungsi otak, termasuk aktivitas abnormal dari sirkuit saraf tertentu dalam otak. Akibat dari depresi tersebut seseorang mengalami penurunan aktifitas, merasa gelisah, sulit berkonsentrasi, daya tahan tubuh menurun, menyendiri dan susah bergaul, putus asa dan bisa juga melakukan hal-hal yang diluar kewajaran.

Menurut Beck (1985), depresi merupakan merupakan "primary mood disorder" atau "affective disorder". Sehingga dapat didefinisikan problem depresi dalam komponenkomponen berikut ini [7]:

1) Depresi merupakan kesedihan yang berkepanjangan. 2) Depresi merupakan cara berfikir yang salah dalam memandang realitas diluar maupun di dalama diri sendiri. 3) Depresi merupakan gangguan terhadap fungsi fisiologis dimana menyebabkan susah tidur dan hilangnya nafsu makan. 4) Depresi merupakan hilangnya kemampuan berfikir secara wajar maupun hilangnya dorongan dan energi untuk bertindak sesuai pikiran sehat. 


\subsection{Metode Certainly Factor}

Shortliffe Buchanan mengenalkan Metode Certainly Factor pada saat pembuatan MYCIN di sekitar tahun 1975. Metode Certainly Factor adalah suatu nilai parameter klinis yang diberikan untuk menunjukkan suatu besarnya tingkat kepercayaan untuk memecahan suatu masalah.

Faktor kepastian (Certainly Factor) merupakan pernyataan suatu kepercayaan dalam sebuah kejadian yang disebut juga dengan fakta atau hipotesis, berdasarkan fakta atau penilaian seorang pakar yang dijelaskan dengan rumus sebagai berikut [8] :

$$
\mathrm{CF}[\text { Rule }]=\mathrm{MB}[\text { H.E }]-\mathrm{MD}[\text { H.E }] . .(2.1)
$$

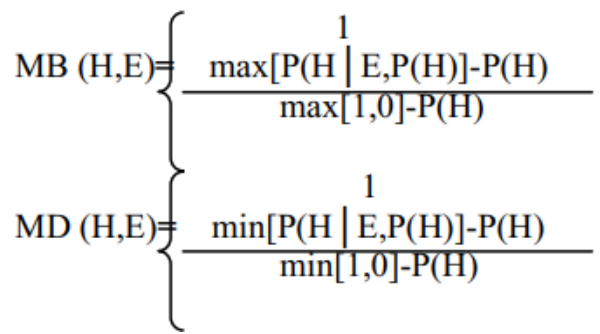

\section{Keterangan}

CF : Certainty Factor

MB : Measure of Belief (ukuran kepercayaan) terhadap hipotesis $\mathrm{H}$, jika diberikan evidence $\mathrm{E}$ (antara 0 dan 1)

MD : Measure of Disbelief (ukuran ketidakpercayaan) terhadap evidence $\mathrm{H}$, jika diberikan evidence $\mathrm{E}$ (antara 0 dan 1)

H : Probability

E : Evidence (peristiwa atau fakta)

\section{HASIL}

\subsection{Analisa Permasalahan}

Untuk penetuan tingkat depresi pada karyawan dapat menggunakan metode Certainty Factor yaitu suatu metode dimana sistem pakar, misalnya seorang psikolog sering menganalisis sebuah informasi dengan ungkapan seperti "hampir yakin", "yakin", "pasti yakin", hal ini digunakan sebagai bentuk untuk menggambarkan sebuah tingkat keyakinan seorang pakar atau ahli terhadap masalah yang seseorang sedang hadapi. Selain itu dalam penelitian ini menggunakan metode wawancara dalam pengumpulan sampel data penelitian, wawancara dilakukan dengan ahli dibidang psikologis

\subsection{Analisa Tingkat Depresi}

Sebelum membuat dan merancang sebuah sistem pakar terhadap tingkat depresi seseorang, penulis perlu menganalisa terhadap karyawan dengan cara memberikan beberapa pertanyaan untuk memudahkan penulis dalam menganalisa tingkat depresi seseorang. Kemudian penulis menentukan gejala tingkat depresi yang dialami mahasiswa semester akhir. Tingkat depresi pada karyawan di sebuah tempat kerja dibagi atas beberapa kriteria yaitu [9]:

1) Minor Depression (Depresi Ringan), ditandai dengan individu yang cemas dan tidak bersemangat. Perubahan gaya hidup menjadi salah satu hal yang dibutuhkan untuk mengurangi depersi jenis ini. Depresi dapat diketahui dua gejala, tetapi tidak lebih dari lima gejala depresi muncul selama dua minggu berturut-turut, dan gejala tersebut bukan disebabkan oleh obatan-obatan atau penyakit. Depresi tingkat ini hanya akan menyebabkan gangguan ringan pada kegiatan atau aktivitas yang biasa dilakukan, sehingga pekerjaan menjadi tidak optimal. Gejala depresi ringan biasanya dirasakan dalam jangka waktu kurang lebih dua tahun.

2) Moderate Depression (Depresi Sedang), yaitu gangguan fungsional yang berada diantara ringan dan berat. Individu mengalami simtom fisik juga meskipun masing-masing individu berbeda. Pada depresi tingkat ini merubah gaya hidup saja tidak cukup sehingga memerlukan bantuan untuk mengatasi depresi pada tingkat ini.

3) Major depression (Depresi Berat), tingkat depresi yang paling parah dan sangat diperlukan untuk mendapatkan bantuan medis secepat mungkin. Individu yang mengalami jenis depresi pada tingkat ini akan sulit menjalankan dan menyelesaikan pekerjaan maupun aktivitas sosial yang biasa dilakukan karena mengalami gangguan dalam menikmati hal yang menyenangkan. Deperesi ini biasanya muncul beberapa kali dalam hidupnya. Major depression dapat diketahui ada lima atau lebih simtom yang ditunjukan dalam major depressive episode dan berlangsung selama kurang lebih 2 minggu secara berturut-turut.

Ada beberapa gejala-gejala pada tingkat depresi antara lain sebagai berikut :
1. Kesedihan
9. Kehilangan Ketertarikan
2. Pesimis
3. Kegagalan
10. Keraguan
11. Kehilangan Energi
4. Kehilangan Kenikmatan
5. Perasaan Bersalah
6. Perasaan di Hukum
12. Perubahan Pola Tidur
13. Perubahan Nafsu Makan
14. Sulit Konsentrasi
7. Pikiran Bunuh Diri
15. Kelelahan

8. Gelisah

Setelah diperoleh tabel gejala, selanjutnya dilakukan pembuatan pohon keputusan dan rulenya [10]:

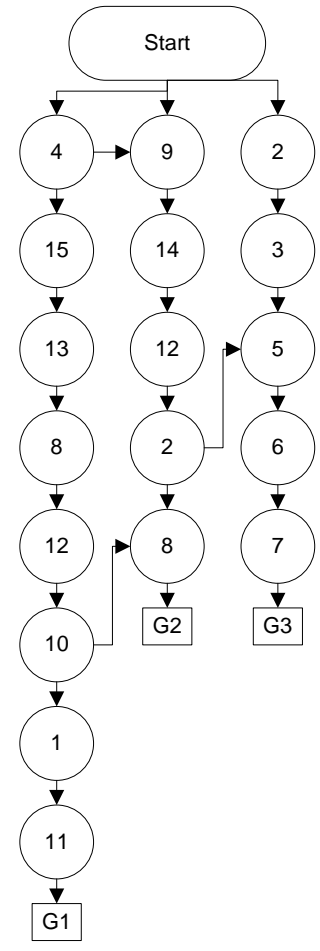

Gambar 1. Pohon Keputusan 
Berdasarkan beberapa gejala diatas maka dapat disusun kaidah produksi yang berhubungan dengan depresi karyawan, kaidah-kaidah adalah sebagai berikut :

Adapun logika perubahan yang masing-masing memiliki bobot yaitu sebagai berikut :

$\begin{array}{lcc}\text { 1. } & \text { Tidak yakin } & 0 \\ \text { 2. } & \text { Tidak Pasti } & 0,2 \\ \text { 3. } & \text { Sedikit yakin } & 0,4 \\ \text { 4. } & \text { Cukup yakin } & 0,6 \\ \text { 5. } & \text { Yakin } & 0,8 \\ \text { 6. } & \text { Sangat yakin } & 1 \\ \text { 7. } & \text { Mungkin tidak } & -0,4\end{array}$

Nilai 0 dapat diketahui bahwa Seseorang yang berkonsultasi akan mengkonfirmasikan bahwa dia tidak memiliki tingkat depresi seperti ditanyakan pada sistem pakar. Semakin sistem yakin pada tingkat depresi tersebut, maka semakin tinggi pula persentase keyakinan yang dihasilkan oleh pengguna konsultasi pada sistem tersebut. Proses perhitungan persentase keyakinan oleh sistem diawali dengan pemecahan suatu kaidah yang memiliki premis tunggal. Kemudian masing-masing aturan akan dihitung dengan metode Certainty Factor, sehingga dapat diperoleh nilai Certainty Factor seseuai dengan masingmasing aturan, kemudian nilai Certainty Factor tersebut dapat dikombinasi.

Untuk menjelaskan seberapa tingkat kepastian seorang pakar terhadap suatu data, maka konsep ini kemudian dihitung dengan rumusan dasar sebagai berikut :

Adapun rule untuk tingkat depresi karyawan pada suatu pekerjaan adalah sebagai berikut :

\section{$\mathrm{CF}[\mathrm{H}, \mathrm{E}]=\mathrm{MB}[\mathrm{H}, \mathrm{E}]-\mathrm{MD}[\mathrm{H}, \mathrm{E}]$ $\mathrm{CF}[\mathrm{H}, \mathrm{E}] 1=\mathrm{CF}[\mathrm{H}]^{*} \mathrm{CF}[\mathrm{E}]$ \\ CF combine $\mathrm{CF}[\mathrm{H}, \mathrm{E}] 1,2=\mathrm{CF}[\mathrm{H}, \mathrm{E}] 1+\mathrm{CF}[\mathrm{H}, \mathrm{E}] 2 *[1-$ $\mathrm{CF}[\mathrm{H}, \mathrm{E}] 1]$ \\ $\mathrm{CF}$ combine \\ $\mathrm{CF}[\mathrm{H}, \mathrm{E}]$ old $3=\mathrm{CF}[\mathrm{H}, \mathrm{E}]$ old $+\mathrm{CF}[\mathrm{H}, \mathrm{E}] 3 *[1-$ $\mathrm{CF}[\mathrm{H}, \mathrm{E}] \mathrm{old}]$}

\author{
IF D2 And D13 \\ Then M1 \\ IF D1 AND D3 \\ AND D5 \\ AND D6 \\ AND D8 \\ AND D10 \\ AND D11 \\ AND D12 \\ AND D14 \\ AND D15 \\ THEN M2 \\ IF D4 AND D7 \\ AND D9 \\ THEN M3
}

Langkah awal pakar atau ahli menentukan CF pada masing-masing gejala yaitu sebagai berikut:
D1pakar $=1,0$
D2 pakar $=0,2$
D3 pakar $=0,8$
D4 pakar $=0,5$
D5 pakar $=0,4$
D6 pakar $=0,3$
D7 pakar $=0,8$
D8 pakar $=0,8$
D9 pakar $=1,0$
D10 pakar $=1,0$
D11 pakar $=0,3$
D12 pakar $=0,8$
D13 pakar $=1,0$
D14 pakar $=0,4$
D15 pakar $=0,2$

Misalkan user memilih jawaban sebagai berikut :

$\begin{array}{lcc}\text { D1 } & \text { Tidak tahu } & 0,2 \\ \text { D2 } & \text { Sedikit yakin } & 0,4 \\ \text { D3 } & \text { Sangat yakin } & 1 \\ \text { D4 } & \text { Sangat yakin } & 1 \\ \text { D5 } & \text { Sedikit yakin } & 0,4 \\ \text { D6 } & \text { Yakin } & 0,8 \\ \text { D7 } & \text { Sangat yakin } & 1 \\ \text { D8 } & \text { Tidak yakin } & 0 \\ \text { D9 } & \text { Sangat yakin } & 1 \\ \text { D10 } & \text { Sedikit yakin } & 0,4 \\ \text { D11 } & \text { Tidak tahu } & 0,2 \\ \text { D12 } & \text { Tidak tahu } & 0,2 \\ \text { D13 } & \text { Sedikit yakin } & 0,4 \\ \text { D14 } & \text { Mungkin tidak } & -0,4 \\ \text { D15 } & \text { Sedikit yakin } & 0,4\end{array}$

Kadah tersebut dihitung nilai CF-nya dengan mengalikan dengan $\mathrm{C}$-fuser dengan CF-pakar menjadi :

$$
\begin{gathered}
=\mathrm{CF}[\mathrm{H}] 1 * \mathrm{CF}[\mathrm{E}] 1 \\
=1,0 * 0,2 \\
=0,2 \\
=\mathrm{CF}[\mathrm{H}] 2 * \mathrm{CF}[\mathrm{E}] 2 \\
=0,2 * 0,4 \\
=0,8 \\
=\mathrm{CF}[\mathrm{H}] 3 * \mathrm{CF}[\mathrm{E}] 3 \\
=0,8 * 1 \\
=0,8 \\
=\mathrm{CF}[\mathrm{H}] 4^{*} \mathrm{CF}[\mathrm{E}] 4 \\
=0,5 * 1 \\
=0,5 \\
=\mathrm{CF}[\mathrm{H}] 5 * \mathrm{CF}[\mathrm{E}] 5 \\
=0,4 * 0,4 \\
=0,16 \\
=\mathrm{CF}[\mathrm{H}] 6 * \mathrm{CF}[\mathrm{E}] 6 \\
=0,3 * 0,8 \\
=0,24 \\
=\mathrm{CF}[\mathrm{H}] 7 * \mathrm{CF}[\mathrm{E}] 7 \\
=0,8 * 1 \\
=0,8
\end{gathered}
$$




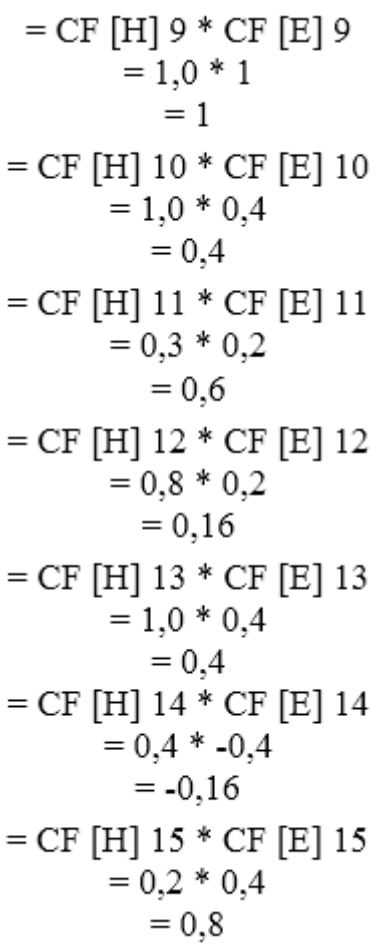

\subsection{Hasil Prediksi Tingkat Depresi}

IF D1 THEN S= Cobalah menyadari bahwa semua orang pada saat yang tertentu juga mengalami hal yang sama seperti Anda rasakan. Yakinkan pada diri, cepat atau lambat kesedihan ini akan berakhir.

IF D2 THEN $\mathrm{S}=$ Jika keyakinan dalam hati sudah mnantap, maka dia menjadi lebih bersemangat berusaha dan optimis serta menatap masa depannya dengan sangat baik. Masa lalu dapat dikatan suram dan banyak masalah. Tetapi, tidak boleh ada alasan hari esok akan tetap seperti saat ini.

IF D3 THEN S= Bersabar apabila mengalami sebuah kegagalan. Karena kegagalan bukan akhir dari segalanya. Anda akan dilatih untuk menjadi pribadi yang lebih kuat dan menjadikan mental berhati baja dari sebelumnya.

IF D4 THEN $\mathrm{S}=$ Cobalah untuk membuka diri dan dapa menerima masukan dari orang lain, tujuannya agar kita tidak selalu terdiam karena terpikir oleh suatu masalah.

IF D5 THEN $\mathrm{S}=$ Perasaan bersalah muncul karena merasa tertekan dari berbagai kewajiban dalam suatu pekerjaan, dengan ini cobalah untuk berpikir positif dan terus mencoba hal yang baru.

IF D6 THEN $\mathrm{S}=$ Perasaan dihukum muncul karena berawal dari kegagalan yang pernah anda alami secara terus menerus, untuk menetralisir keadaan itu perlu adanya dukungan dari orang lain yang berada di lingkungan kerja kita atau terdekat kita, berusahalah terus karena sejatinya itu adalah ujian hidup yang harus anda lewati.

IF D7 THEN $\mathrm{S}=$ Gunakan pemikiran Anda sebagai pribadi yang dewasa. Jangan memikirkan masalah atau pemecahannya, akan baiknya kita bergerak ke jalan yang baru: jangan memikirkan masalah itu dahulu. Dengan ini, gunakanlah kesadaran anda dengan sepenuhnya sebagai yang diciptakan Allah SWT, maka dengan kesadaran yang anda miliki, anda harus mampu mengatakan, "masalah Ini bisa diselesaikan".

IF D8 THEN S=Halangan, jangan dihindari tapi harus tetap dihadapi. Hidup itu adalah tantangan itu adalah sebuah masalah. Mengapa kita harus menghindarinya? Di sinilah kadang-kadang kita lupa pada kesejatian diri kita. Selalu berusaha dan katakan dalam hati ini pasti berahir dengan kesuksesan.

IF D9 THEN $\mathrm{S}=$ Jangan selalu terdiam karena masalah yang kita hadapai, masih banyak yang harus anda lakukan cobalah bangkit dari keterpurukan.

IF D10 THEN S=Sebetulnya, semangat yang kuat itu diperlukan untuk mengatasi semua keraguan dan cobaan yang bisa mematikan kesungguhannya untuk mencapai hal-hal penting atau besar yang diinginkannya dalam meraih kesuksesan kerja.

IF D11 THEN S= Yang Jelas, Setiap masalah yang ada dihadapan Anda, insyallah akan ada jalan keluarnya untuk dapat dipecahkan. Anda pasti tahu apa yang anda harus lakukan untuk menghadpi suatu masalah di hadapan anda. Bergerak dan memerangi suatu masalah anda dengan yakin terhadap kepercayaan diri anda untuk bisa mengatasinya.

IF D12 THEN $S=$ Susah tidur adalah hal yang nampak dari gejala atau akibat dari depresi yang anda alami. Karena otak menggunakan salah satu syaraf serupa untuk mengatur tidur dan emosi, cukup sulit untuk menentukan mana yang harus dilakukan terlebih dulu.

IF D13 THEN S=Pikirkan dan renungkan bagaimana rasa malas ini dapat mempengaruhi kualitas dan kuantitas hidup Anda, hubungan sosial, kesehatan dan energi yang memburuk, serta membuat anda kehilangan kesempatan dalam pekerjaan. Buatlah daftar data apa saja yang dapat Anda lakukan untuk menghilanginya rasa malas tersebut. Jangan biarkan diri anda tersiksa, karena anda masih dibutuhkan banyak orang terdekat anda.

IF D14 THEN $S=$ Anda harus belajar untuk menyakinkan diri anda untuk membatasi suatu pekerjaan. Jika Anda dapat menemukan konsentrasi lebih dalam bekerja, maka lakukan hal yang mudah ini, Ambil nafas dalam-dalam dan perlahan keluarjab. Ketika mengambil nafas, seketika itu otak akan terstimulasi masuk pada tekanan atau frekwensi yang rendah.

IF D15 THEN S=Kelelahan anda muncul disebabkan karena pikiran anda yang lelah untuk memikirkan masalah pekerjaan ini. Jadi, cobalah untuk menenangankan diri anda dengan istirahat atau dengan mencari tempat yang bisa membuat anda tenang untuk sementara waktu.

\section{KESIMPULAN}

\subsection{Kesimpulan}

Demikian kesimpulan yang diperoleh dari hasil penelitian sebagai berikut :

1) Gejala-gejala depresi yang terjadi pada karyawan dari 15 gejala dapat disimpulkan bahwa kurang semangat nya beraktifitas dalam keseharian menjadi faktor utama menentukan tingkat depresi seorang karyawan terhadap pekerjaannya.

2) Penggunaan atau Penerapan metode certainty factor dapat digunakan karena metode ini memiliki algoritma 
dalam menentukan seberapa besar tingkat keyakinan atau kepastian terhadap depresi dari seorang karyawan terhadap pekerjaanya.

4.2. Saran

Ada beberapa saran yang dapat diperoleh dari kami sebagai penulis antara lain sebagai berikut :

1) Dalam pengembangan sistem pakar dapat diaplikasikan diberbagai bahasa pemrograma maupun konsep (mobile app, web, dekstop)

2) Beberapa komponen-komponen dari sistem pakar ini cukup banyak memiliki kekurangan utamanya pada gejala-gejala depresi dan solusi dari setiap permasalahan yang belum maksimal serta masih perlu banyaknya pengembangan.

\section{DAFTAR PUSTAKA}

[1] M. A. Krisdianto, "Mekanisme Koping Berhubungan dengan Tingkat Depresi pada Mahasiswa Tingkat Akhir," no. 3, hal. 71-76.

[2] F. Rahmi Ras, H. Nelly Astuti, dan B. Efori, "Perancangan Sistem Pakar Diagnosa Penyakit Asidosis Tubulus Renalis Menggunakan Metode Certainty Factor Dengan Penelusuran Forward Chaining," Media Inform. Budidarma, vol. 1, no. 1, hal. 13-16, Feb 2017.

[3] C. Zhao, W. Chen, Q. Wang, Y. Wu, dan B. Yang, "A comparative study of statistical index and certainty factor models in landslide susceptibility mapping: a case study for the Shangzhou District, Shaanxi Province, China," Arab. J. Geosci., vol. 8, no. 11, hal. 9079-9088, Nov 2015.

[4] T. N. Oktavia, D. H. Satyareni, E. N. Jannah, S. Informasi, dan F. Teknik, "Rancang Bangun Sistem Pakar Untuk Mendiagnosis Gangguan Kepribadian Histerik Menggunakan Metode Certainty Factor," vol. 1, hal. 15-23.

[5] H. Hong, W. Chen, C. Xu, A. M. Youssef, B. Pradhan, dan D. Tien Bui, "Rainfall-induced landslide susceptibility assessment at the Chongren area (China) using frequency ratio, certainty factor, and index of entropy," Geocarto Int., vol. 32, no. 2, hal. 139-154, Jan 2017.

[6] N. Qonitatin, S. Widyawati, dan G. Y. Asih, "INTERVENSI DEPRESI RINGAN PADA MAHASISWA," 2001.

[7] W. Chen, H. R. Pourghasemi, A. Kornejady, dan X. Xie, "GIS-based landslide susceptibility evaluation using certainty factor and index of entropy ensembled with alternating decision tree models," in Advances in Natural and Technological Hazards Research, vol. 48, Springer, Cham, 2019, hal. 225-251.

[8] K. N. Sistem, A. Astuti, dan J. R. Utara, "Sistem Pakar Untuk Mengetahui Gangguan Depresi Mayor Dengan Menggunakan Faktor Kepastian,” hal. 9-10, 2015.

[9] J. A. Widians dan M. Wati, “APLIKASI SISTEM PAKAR TINGKAT DEPRESI CERTAINTY FACTOR,” hal. 4-9, 2017.

[10] G. Virgian dan G. Putri, "Sistem Pakar Diagnosa Mental Ilness Psikosis dengan Menggunakan Metode Certainty Factor," hal. 164-168, 2018. 